\title{
Human and animal brucellosis in Yemen
}

\begin{abstract}
The aims of this review were to characterize human and animals brucellosis epidemiology in Yemen and also guide policy makers to draw sound decisions regarding brucellosis control policies. The Seroprevalence of human brucellosis in Yemen was ranging from 0.3 to $32.3 \%$. Nevertheless, it is suggested that a stronger inter-sectoral collaboration among pregnant women, veterinary, medical and public health professionals and country level in terms of one-health approach should be promoted. In spite of this disease is reported in humans and all domestic animals of the country, Yemeni people lack awareness about the zoonotic potential of the disease with their existing habit of raw milk consumption and close contact with domestic animals.
\end{abstract}

Keywords: Brucellosis, Human, Animal, Review, Yemen
Volume 5 Issue 4 - 2017

\author{
Saad Al-Arnoot, ${ }^{1,2}$ Qais YM Abdullah,' Salwa \\ H Alkhyat,' Anas A Almahbashi,' Mofeed Al \\ Nowihi' \\ 'Department of Biology, Sana'a University, Yemen \\ ${ }^{2}$ Department Microbiology, Egyptian Pharma Co Itd, Yemen
}

Correspondence: Saad Al-Arnoot, Microbiology Division, Department of Biology, Faculty of Science, Sana'a University, Sana'a, Yemen, Tel 00967774667900 ,

Email saad.alarnoot@gmail.com

Received: April 06, 2017| Published: May 23, 2017
Abreviations: CC, Case-Control; CFT, Complement Fixation Test; CS, Cores Sectional; ELISA, Enzyme Linked Immunosorbent Assay; RBPT, Rose Bengel Plate Test; SAT, Serum Agglutination Test; STA, Standard Tube Agglutination

\section{Introduction}

Brucellosis is a worldwide zoonotic disease affecting both animals and humans. It also known as "Malta fever", "undulant fever", or "Mediterranean fever". ${ }^{1}$ Brucellosis caused by Brucella which is a small, gram-negative, coccobacilli, aerobic, facultative intracellular, non-motile, non-fermenting, non-spore-forming, non-fermenting, ${ }^{2,3}$ Four species cause human disease: B. abortus in cattle and buffalo, B. canis in canine, B. suis in pigs, and B. melitensis in sheep, goats and camels which is the most virulent and the principle cause of human infection. ${ }^{1,4}$ Brucella can be found in both domestic and wild animals. It is transmitted to humans through direct or indirect contact with infected animals or their products. . $^{1,5,6}$ Portals of entry of the organism are the conjunctiva respiratory mucosa and damaged skin. ${ }^{7}$ The transmission from person to person is uncommon, but the infection from human sources may occur in the following ways:

a. Vertical transmission with placental circulation, breast feeding, blood transfusion, bone marrow transplantation the and sexual contact. ${ }^{8}$

b. Brucellosis is endemic in the Middle East, south and central Asia, north and east Africa, Mediterranean countries of Europe, and central and South America. Worldwide, reported incidence of human brucellosis in endemic disease areas varies widely, from $<0.01$ to $>200$ per 100,000 population 5

c. The incidence of human brucellosis in most countries is unknown and it has been estimated that the incidence may be 25 times higher than the reported incidence due to misdiagnosis and underreporting. ${ }^{9}$

In Yemen, there is a little information of animal and human brucellosis. The serological investigations and bacteriological isolations of Brucellacarried on the country are very scarce. In spite the disease is reported in all domestic ruminants of the country, Yemeni people lack awareness about the zoonotic potential of the disease with their existing habit of raw milk consumption and close contact with domestic animals. Destruction of human and animals brucellosis by test-and-slaughter is impracticable in developing countries including
Yemen because of limited resources to compensate farmers whose animals are slaughtered during such screening programs. Also, the national program is not available for prevention and control of brucellosis in the country. Only, there is one veterinary lab for animals which located in Sana'a. The main obstacles limiting the control of the disease are: security of the country, shortage of funds, laboratory facilities and trained manpower. So, this review article aims to describe an overview on brucellosis situation of the country and supports brucellosis interesting researchers to more understand the disease situation in the country. It also guides policy makers to draw sound decisions regarding brucellosis control policies.

\section{Human brucellosis in Yemen}

Until now, no attempts have been made of Brucella isolation, identification of genotypes and estimation of disease burden in human host in Yemen. The results of local prevalence studies done in human (Table 1) are summarized below.

\section{Epidemiology}

Studies on the prevalence of brucellosis in the general human population are limited in number. The Seroprevalence of human brucellosis in these studies was ranging from 0.3 to $32.3 \%$. The first report was conducted a survey of Brucella antibodies among Yemeni blood donors. It investigated 1405 human serum samples using serum agglutination test (SAT) and revealed $0.4 \%$ positive. The prevalence founded from this study was in different localities which are Sana'a $0.7 \%$, Taiz $0.8 \%$ and Hajja $0.35 \% .{ }^{10}$ In Saleh. ${ }^{11}$ Used STA to tested 385 human serum samples from slaughterhouse workers in different areas in Yemen, who reported a high prevalence of Brucella antibodies were $27 \%$. $32.3 \%, 25.5 \%, 25.7 \%, 26.2 \%$ and $22.2 \%$ positive in Sana'a, Aden, Taiz, AL- Hodeidah, Ibb and Hajjah respectively. Another study conducted in Sana'a used STA to tested 215 of serum samples and it showed $10.1 \%$ and $24.4 \%$ positive for males and females brucellosis respectively. ${ }^{12}$ The lower than prevalence of human brucellosis was conducted in Shabwah city with prevalence $2.2 \%$ in males and $1.6 \%$ in females. ${ }^{13}$ In Al- Dala'a city the crude sero-prevalence of brucellosis among tested individuals was $6.7 \%$ for male was $5.5 \%$, lower than that of female $7.2 \%$. Among 749 asymptomatic individuals from 3 randomly selected areas were included in the study. ${ }^{14}$

\section{Risk factors}

Epidemiologic studies have identified the following risk factors for Brucella infection in general population which conducted in 
different localities in Yemen. The results of the studies on human brucellosis show significant risk factors for infection were found to relate to occupation as a farmer, shepherd and microbiologist. ${ }^{15}$ The highly significant risk factors for infection were related to be associated with ownership of livestock animals. ${ }^{14}$ Contact with placental membrane, clearing viscera of animals. ${ }^{12}$ And direct contact with animals execration or products (Milking, Handling new born, animal slaughter) and indirect contact with livestock (drinking unpasteurized milk. ${ }^{12,14,15}$ Drinking labban. ${ }^{14,15}$ Ingestion local chees, ingestion raw liver and ingestion raw spleen). ${ }^{14}$

\section{Animals brucellosis in Yemen}

The serological investigations of Brucella carried on the country are scarce. The results of local prevalence studies done in animals (Table 2) are summarized below.

Table I Studies reporting prevalence of human brucellosis in Yemen

\begin{tabular}{|c|c|c|c|c|c|c|c|}
\hline \multirow{2}{*}{$\begin{array}{l}\text { Authors } \\
\text { Al- Shamahy [10] }\end{array}$} & \multirow{2}{*}{$\begin{array}{l}\text { Population } \\
\text { Blood donors }\end{array}$} & \multirow{2}{*}{$\begin{array}{l}\text { City } \\
\text { Sana'a }\end{array}$} & \multirow{2}{*}{$\begin{array}{l}\text { Sample Size } \\
300\end{array}$} & \multicolumn{2}{|c|}{ Type of StudyMethods } & \multicolumn{2}{|c|}{ Duration of Study Prevalence } \\
\hline & & & & CS & SAT & 1993 & $0.70 \%$ \\
\hline Al- Shamahy [10] & Blood donors & Taiz & 240 & CS & SAT & 1993 & $0.80 \%$ \\
\hline Al- Shamahy [10] & Blood donors & Hajjah & 290 & CS & SAT & 1993 & $0.30 \%$ \\
\hline Al- Shamahy [10] & Blood donors & Molalla & 287 & CS & SAT & 1993 & $0 \%$ \\
\hline Al- Shamahy [10] & Blood donors & Hodeidah & 288 & CS & SAT & 1993 & $0 \%$ \\
\hline Nasher [12] & Males & Sana'a & 169 & CS & STA & $2005-2006$ & $10.10 \%$ \\
\hline Agrah [13] & Males & Shabwah & 522 & CS & STA & $2010-2011$ & $2.20 \%$ \\
\hline Al-Haddad et al. [14] & Males & Al- Dala'a & 237 & CS & STA & $2009-2010$ & $5.50 \%$ \\
\hline Nasher (I2) & Females & Sana'a & 215 & CS & STA & $2005-2006$ & $24.40 \%$ \\
\hline Agrah (I3) & Females & Shabwah & 522 & CS & STA & $2010-2011$ & $1.60 \%$ \\
\hline Al-Haddad et al. [14] & Females & Al- Dala'a & 512 & CS & STA & $2009-2010$ & $7.20 \%$ \\
\hline AL-Shamahy et al. [15] & General population & Sana'a & 253 & $\mathrm{CC}$ & STA & 1993 & $7.90 \%$ \\
\hline Saleh [II] & Slaughterhouse & Sana'a & 75 & CS & STA & $1999-2000$ & $27 \%$ \\
\hline Saleh [II] & Slaughterhouse & Aden & 30 & CS & STA & $1999-2000$ & $32.30 \%$ \\
\hline Saleh [II] & Slaughterhouse & Taiz & 90 & CS & STA & $1999-2000$ & $25.50 \%$ \\
\hline Saleh [II] & Slaughterhouse & Hodeidah & 70 & CS & STA & $1999-2000$ & $25.70 \%$ \\
\hline Saleh [I I] & Slaughterhouse & $\mathrm{lbb}$ & 84 & CS & STA & $1999-2000$ & $26.20 \%$ \\
\hline Saleh [II] & Slaughterhouse & Hajjah & 36 & CS & STA & $1999-2000$ & $22.20 \%$ \\
\hline
\end{tabular}

CC: Case Control; CS: Cores Sectional; SAT: Serum Agglutination Test; STA: Standard Tube Agglutination

Table 2 Studies reporting prevalence of animal brucellosis in Yemen

\begin{tabular}{|c|c|c|c|c|c|c|}
\hline Authors & Type of animals & City & Sample size & Methods & Duration of study & Percentage \\
\hline Hosie et al. [20] & Sheep & Sana’a & 210 & RBPT/CFT/SAT & 1980- 1982 & $30 \%$ \\
\hline Nagi [19] & Sheep & Sana'a & 150 & RBPT/ELSIA & 2003 & $2.00 \%$ \\
\hline Nagi [19] & Sheep & Sa'ada & 150 & RBPT/ELSIA & 2003 & $4.00 \%$ \\
\hline Nagi [19] & Sheep & Amran & 150 & RBPT/ELSIA & 2003 & $4.00 \%$ \\
\hline Hosie et al. [20] & Sheep & Hodeidah & 371 & RBPT/CFT/SAT & 1980- 1982 & $44 \%$ \\
\hline Hosie et al. (20) & Sheep & Dhamar & 109 & RBPT/CFT/SAT & 1980- 1982 & $16 \%$ \\
\hline Agrah [13] & Sheep & Shabwaha & 251 & TSA & 2010 & $3.30 \%$ \\
\hline Al-Shamahy [I7] & Sheep & - & 12 & ELSIA & 1992- 1993 & $0.60 \%$ \\
\hline Hosie et al. [20] & Sheep & Other city & 67 & RBPT/CFT/SAT & 1980- 1982 & $10 \%$ \\
\hline Hosie et al. [20] & Goats & Sana'a & 259 & RBPT/CF T/SAT & 1980- 1982 & $48 \%$ \\
\hline Nagi [19] & Goats & Sana’a & 150 & RBPT/ELSIA & 2003 & $1.30 \%$ \\
\hline Nagi [19] & Goats & Sa'ada & 150 & RBPT/ELSIA & 2003 & $3.30 \%$ \\
\hline Nagi [19] & Goats & Amran & 150 & RBPT/ELSIA & 2003 & $2.70 \%$ \\
\hline Hosie et al. [20] & Goats & Hodeidah & 143 & RBPT/CFT/SAT & $1980-1982$ & $27 \%$ \\
\hline Hosie et al. [20] & Goats & Dhamar & 136 & RBPT/CFT/SAT & 1980- 1982 & $1 \%$ \\
\hline Agrah [13] & Goats & Shabwaha & 270 & TSA & 2010 & $7.40 \%$ \\
\hline Al-Shamahy [I7] & Goats & - & 26 & ELISA & 1992- 1993 & $1.30 \%$ \\
\hline Hosie et al. [20] & Goats & Other & 130 & RBPT/CF T/SAT & 1980- 1982 & $24 \%$ \\
\hline Al-Garadi et al. [I8] & Camels & Hodeidah & 295 & RBPT & 2015 & $11 \%$ \\
\hline Al-Garadi et al. [18] & Camels & Hodeidah & 295 & A-fibril antigen & 2015 & $5 \%$ \\
\hline Al-Garadi et al. [18] & Camels & Hodeidah & 295 & M-febrile antigen & 2015 & $6 \%$ \\
\hline Al-Garadi et al. [18] & Camels & Hodeidah & 295 & MRT & 2015 & $5.10 \%$ \\
\hline Agrah [13] & Camels & Shabwah & 15 & TSA & $2010-2011$ & $6.70 \%$ \\
\hline Al-Shamahy [I7] & Camels & - & 105 & ELSIA & 1992- 1993 & 0 \\
\hline Nagi [19] & Cattle & Sana’a & 150 & RBPT/ELSIA & 2003 & $3.30 \%$ \\
\hline Nagi [19] & Cattle & Sa'ada & 150 & RBPT/ELSIA & 2003 & $1.30 \%$ \\
\hline Nagi [19] & Cattle & Amran & 150 & RBPT/ELSIA & 2003 & $0.70 \%$ \\
\hline Al-Shamahy [I7] & Cattle & - & I & ELSIA & 1992- 1993 & $0.06 \%$ \\
\hline
\end{tabular}

CFT: Complement Fixation Test; ELSIA: Enzyme-Linked Immunosorbent Assay; RBPT: Rose Bangel Plate Test; SAT: Serum Agglutination Test; STA: Standard Tube Agglutination 


\section{Clinical brucellosis}

Studies on the clinical of brucellosis in the general human population are limited in number. The only published paper on clinical brucellosis by Al- Shamahy et al. ${ }^{16}$ Whose studded 235 cases of human brucellosis in Sana'a 132 cases were male and 103 female giving male: female ratio of 1.3: $1.0 \%$ respectively. The overall clinical picture of brucellosis is very similar to that reported by other workers in this geographical area. These data suggest that male and female exposure to the risk of infection is about the same, and that the activities associated with exposure are performed by both sexes or that they are exposed to the same reservoir of infection animals but at different point in the cycle of contact.

\section{Camel brucellosis}

Only three serological investigations of camel brucellosis in Yemen were available. The first study reported the prevalence of camel brucellosis was not recorded any cases of this disease from 105 camels sample that tested by using ELISA. ${ }^{17}$ In Agrah $^{13}$ carried out sero-agglutination test on 250 serum samples from camels in Shabawah. Who estimated that 15 of $536(6.7 \%)$ sera tested for positive Brucella antibodies in central regions of Yemen, Al-Garadi et al. ${ }^{18}$ investigated serologically 295 camels for brucellosis using RBPT, A-fibril antigen, M-febrile antigen, and MRT. Who found the prevalence of Brucella was $11 \%, 5 \%, 6 \%$ and $5.1 \%$ respectively. The highest prevalence of camel brucellosis was recorded $11 \%$ in Hodeida region of Yemen by using RBPT for detection of brucellosis.

\section{Cattle Brucellosis}

The prevalence of bovine brucellosis in the country was firstly carried out by Al-Shamahy. ${ }^{17}$ Which was recorded that out of 1645 cattle was $0.06 \%$ Brucella antibodies positive by using ELISA as a diagnostic test. Nagi ${ }^{19}$ carried out 450 serum samples from cattle of Northern parts of the country (Sana'a, Sa'ada and Amran). Who used RBPT and ELSIA for the presence of Brucella infection. The overall prevalence of regions under investigation was 3.3\%, 1.3\% and $0.7 \%$ in Sana'a, Sa'ada and Amran respectively. He found marked differences in regional distribution of bovine brucellosis. The highest sero-prevalence $(3.3 \%)$ was recorded in the cattle population of the Sana'a city, but Sa'ada and Amran regions are comparable to each other, $1.3 \%$ and $0.7 \%$ respectively.

\section{Sheep and goat brucellosis}

In Yemen, there is a few information about isolation of Brucella fron animal. Only one study conducted on isolation of brucella. It was reported that $B$. melitensis biotype 2 has been isolated from sheep (the isolate was confirmed by the $\mathrm{FAO} / \mathrm{WHO}$ collaborating center for reference and research on Brucellosis, Weybridge, and Surrey, United Kingdom. ${ }^{17}$ Although the first report on the serological of Brucella antibodies in the country were recorded in 1985 by Hosie and his colleagues. ${ }^{20}$ Who tested 690 sheep and 538 goat serum samples obtained from Hodeidah, Dhamar and Sana'a. They used three methods to determine the prevalence of brucellosis include; RBPT, CFT and SAT test. The results found were $30 \%, 44 \%$ and $16 \%$ of the total number of samples examined positive for brucella respectively. Al-Shamahy ${ }^{17}$ used ELISA to examined 2045 sheep and 2014 goats kept on free range in the country who found the results revealed were 12 out of 2045 positive $(0.6 \%)$ in sheep and 26 of $2014(1.3 \%)$ in goats. In Nagi ${ }^{19}$ tested 450 sheep and 450 goats from Sana'a, Sa'ada and Amran in the north of the country. Who showed the prevalence of sheep brucellosis were 2.0\% in Sana'a, $4.0 \%$ in Sa'ada and $4.0 \%$ in Amran of northern Yemen while the prevalence of goats brucellosis were $1.3 \%$ in Sana'a, in Sa'ada $3.3 \%$ and $2.7 \%$ in Amran, Agrah. ${ }^{13}$ Documented prevalence of $3.3 \%$ in sheep, and $7.4 \%$ in goats in Shabwah region of southern Yemen by using TSA.

\section{Conclusion}

In conclusion, this paper indicated that the knowledge of brucellosis is still very scanty and no epidemiological importance in Yemeni people. Brucella infection exists within the livestock of the country, and Yemeni people drink raw milk and have a close contact with domestic animals which are the risk factors of brucellosis. This review article recommends an educational program and leaflet should be established to aware the people by the risk of Brucella infection, further studies of serological diagnosis and bacteriological isolation of the disease and collaboration among general population especial in pregnant women, veterinary, medical and public health professionals in terms of research and extension services.

\section{Acknowledgments}

None.

\section{Conflicts of interest}

None.

\section{References}

1. Corbel M, Elberg S, Cosivi O. Brucellosis in humans and animals. World Health Organization, Switzerland. 2006;pp.1-102.

2. Grimont F, Verger JM, Cornelis P, et al. Molecular typing of brucella with cloned DNA probes. Res Microbiol. 1992;143(1):55-65.

3. Moreno E, Stackebrandt E, Dorsch M, et al. Brucella abortus 16S rRNA and lipid A reveal a phylogenetic relationship with members of the alpha-2 subdivision of the classs Proteobacteria. $J$ Bacteriol. 1990;172(2):3569-3576.

4. Lopes LB, Nicolino R, Haddad JPA. Brucellosis - risk factors and prevalence: a review. The Open Veterinary Science Journa. 2010;4:72-84

5. Boschiroli ML, Foulongne V, O'Callaghan D. Brucellosis a worldwide zoonosis. Curr Opin Microbiol. 2001;4(1):58-64.

6. Chen S, Zhang H, Liu X, et al. Increasing threat of brucellosis to low-risk persons in urban settings. China Emerg Infect Dis. 2014;20(1):126-130

7. Mesner O, Riesenberg K, Biliar N, et al. The many faces of human-tohuman transmission of brucellosis: congenital infection and outbreak of nosocomial disease related to an unrecognized clinical case. Clin Infect Dis. 2007;45(12):135-140.

8. Peker N, Volkan T, Mete E, et al. Brucellosis in adolescent pregnancy case report and review of literature. Ginekol Pol. 2011;82(3):226-229.

9. Corbel M. Brucellosis in humans and animals. World Health Organization, Switzerland. 2006.

10. Al-Shamahy H. Seropositivity for brucellosis in a sample of animals in the Republic of Yemen. East Mediterr Health J. 1999;5(5):1042-1044.

11. Saleh NAA. Seroprevalence of brucellosis among slaughterhouse workers in the Republic of Yemen. Sana'a University, Yemen. 2000.

12. Nasher AAM. Brucellosis in human associated with animals in Sana'aYemen and in laboratory prepared antigen for antibody detecte. Sana'a University, Yemen. 2006.

13. Agrah MASS. Seroprevalence of human and animal brucellosis in selected areas of Shabwah Governorate. Sana'a University, Yemen. 2011. 
14. Al-Haddad AM, Al-Madhagi A, Talab AA, et al. Prevalence of human brucellosis in three selected areas at Al-Dhala'a Governorate. Sana'a University. 2013;25:61-71

15. Al-Shamahy H, Whitty CJM, Wright SG. Risk factors for human brucellosis in Yemen: a case control study. Epidemiol Infect. 2000;125(2):309-313.

16. Al-Shamahy H, Wright SG. A study of 235 cases of human brucellosis in Sana'a, Republic of Yemen. East Mediterr Health J. 2001;7(1-2):238-246

17. Al-Shamahy H. Seropositivity for brucellosis in a sample of animals in the Republic of Yemen. East Mediterr Health J. 1999;5(5):1042-1044.
18. Al-Garadi MA,Al-hothi A,Al-sharmaA. Bacteriological and serological study on brucellosis infection in camel (Camelus dromedaries), AlHodeida governorate, Yemen. Int J Adv Res. 2015;3(1):786-791.

19. Nagi SDG. Brucellosis in Yemen and Sudan seroprevalence, causative agent and evalution of different methods of diagnosis. University of Khartoum, Sudan. 2003.

20. Hosie BD, Al-Bakri OM, Futter RJ. Survey of brucellosis in goats and sheep in the Yemen Arab Republic: comparison of tests for Brucella melitensis infection in sheep. Trop Anim Hlth Prod. 1985;17(2):93-99. 